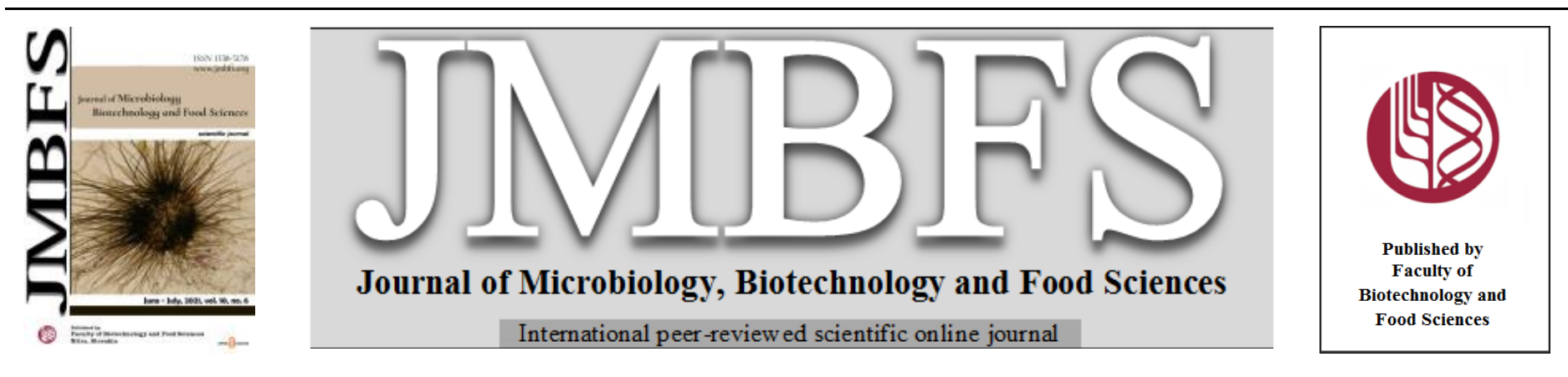

\title{
THE RELATIONSHIP BETWEEN HIGH CONSUMPTION OF FRESH WHOLE MILK OR YOGURT AND THE RISK FOR BOTH CARDIOVASCULAR DISEASES AND LIVER DISORDERS IN HYPERLIPIDEMIC WISTAR RATS
}

\author{
Maha H. Mahmoud ${ }^{*}$, Ibrahim Hassan Badawy, Fatma El-Zahraa Sayed Mohammed \\ Address(es): Prof. Maha H. Mahmoud \\ Nutrition and Food Sciences Dept., National Research Centre, 33 EL-Bohouth St., Dokki, Cairo, Egypt, P.O.12622.
}

*Corresponding author: mahahanafymmm@yahoo.com

https://doi.org/10.15414/jmbfs.3485

\section{ARTICLE INFO}

Received 21. 7. 2020

Revised 3. 1. 2021

Accepted 8. 1. 2021

Published 1. 6. 2021

Regular article

open $O$ access

\begin{abstract}
A rapid increase in the prevalence of hyperlipidemia was recorded recently. The link between consumption of milk or dairy products with higher risk for cardiovascular diseases (CVD) and liver disorders particularly in those individuals with hyperlipidemia is still controversial. The present study was conducted to show the relationship between increased consumption of milk and yogurt either of cow or buffalo origin and the risk for cardiovascular diseases and liver disorders in hyperlipidemic rats. An animal experiment was conducted on six groups each comprising six rats after a period of eight weeks for induction of hyperlipidemia. Then, four groups of the hyperlipidemic rats were fed on $30 \%$ of milk (either buffalo or cow) or yogurt (either buffalo or cow) for another 8 weeks in addition to control negative and control positive groups. Results for the hyperlipidemic groups which received milk or yogurt revealed a reduction in most of serum lipid parameters, atherogenic index, malondialdehyde while increased HDL-C concentration. Also, a reduced activity of liver enzymes ALT, AST and LDH-5 and the cardiac enzyme CPK was noticed for the same groups in comparison with the group of control positive. Histopathological examination for liver and aorta confirmed the aforementioned biochemical changes. Thus, it can be concluded that increased milk or yogurt consumption did not increase the risk for cardiovascular diseases or liver disorders in hyperlipidemic rats. On the contrary, it improves the enzyme activity of both liver and heart and the atherogenic index, also it improves the disturbed serum lipid parameters of hyperlipidemic rats.
\end{abstract}

Keywords: hyperlipidemia, milk, yogurt, CVD, liver disorders, CPK, LDH-5

\section{INTRODUCTION}

Hyperlipidemia is increasing rapidly nowadays in developed countries and in developing nations as they acquire Western habits of increasing consumption of diets of Western-style with elevated saturated and trans fats and sedentary life style. It is currently epidemic worldwide (Mozaffarian et al., 2016). Other factors like race, gender and genetic predisposition may participate as etiologic factors for hyperlipidemia, although conflicting data in this respect are reported (Karr, 2017 \& Yang et al., 2020). In addition to its being a precursor for steatosis or fatty liver disease, it is considered as an important risk factor for the cardiovascular diseases (CVD) (El-Maksoud et al., 2020). The latter is considered as the leading cause for death in the United States (Millar et al., 2020). Hyperlipidemia is characterized by the abnormality in lipid metabolism as well as fat transport problems (Liu et al., 2018). Also, it includes the imbalance between the serum levels of the low-density lipoprotein cholesterol (LDL-C) and the high-density lipoprotein cholesterol (HDL-C) (Karr, 2017). Estimates for prevalence of hyperlipidemia according to World Health Organization in 2008 were $30.3 \%$ for the Southeast Asia, 36.7\% for the Western Pacific, $53.7 \%$ for Europe and $47.7 \%$ for the Americas (Lin et al., 2018). Compared to other countries, Egypt has recorded a high prevalence of hyperlipidemia which reached up to $71 \%$ in female participants as reported from the data collected from the project of CardioRisk that was conducted recently throughout Egypt (Reda et al., 2020).

Dietary factors are the most important risk factors for hyperlipidemia and hence cardiovascular and hepatic diseases. Managing of the levels of blood lipids by dietary modification has been recommended as a primary strategy for prevention. About 1 in each 5 deaths worldwide (aproximately11 million) is correlated to unhealthy eating habits, comprising up to 10 million out of these deaths recorded from CVD (Millar et al., 2020). The contribution of milk and dairy products consumption, with their high saturated fat content, in CVD development is still contradictory up till now (He et al., 2020). Some studies suggest that no associations are found between risk of CVD and dairy consumption (Chartier $\boldsymbol{e} t$ al., 2017 \& Fontecha et al., 2019), while other meta-analysis reported an inverse correlation between CVD risk in women and high consumption of dairy products and milk (Mishali et al., 2019). Others have accused milk fat to be atherogenic as it increases the risk of CVD in the developed countries (Sacks et al., 2017).

Milk and all dairy products are nutritious foods. Milk is an important liquid food that has a distinct quantity of macronutrients and micronutrients of high bioactivity as it provides with energy, protein of high quality and essential minerals and vitamins, also it is inexpensive and readily accessible (UscangaDomínguez et al., 2019 \& He et al., 2020). A large variety of milk types are found in the market but the most popular and commonly used are the cow and buffalo milk and in particular the cow milk. They differ to some extent in their fat composition qualitatively and quantitatively (Halaby $\boldsymbol{e t}$ al., 2015). Although cow milk is an important and common food for human diet, particularly for children and elder people, yet nutritionists have criticized it as its content of fat is mainly formed of saturated fatty acids (SFA) whose increased consumption is believed to be associated with higher incidence of CVD (Santos et al., 2017). Buffalo milk may include almost all the valuable compounds present in other milks, e.g., fatty acids, peptides, proteins, vitamins, and other bioactive components. Buffalo milk contains higher levels of conjugated linoleic acid (CLA), total protein, medium chain fatty acids and higher contents of tocopherols and retinol more than those of the cow milk (Ahmad et al., 2013). Other components which may only be found in buffalo milk are certain classes of gangliosides (Berger $\boldsymbol{e t}$ al., 2005). Besides its advantage of being a rich source for nutrients, Sheehan $\boldsymbol{e t}$ al. (2009) reported that subjects suffering from cow milk allergy can tolerate the buffalo milk.

Yogurt is a food that is produced by bacterial fermentation process of milk. It is one of the most widely consumed fermented dairy products and the most popular all over the world and its consumption has risen considerably by time due to its well-known health benefits (Hassan \& Amjad, 2010). Yogurt consumption delivers to the gastrointestinal tract a huge number of probiotics with great beneficial effects. Several mechanisms are found for these beneficial effects including lowering the inflammatory and oxidative hepatic damage, as well as reducing liver triglycerides. Moreover, probiotics improve the state of dyslipidemia and minimize insulin resistance (Zhang et al., 2020)

As milk and dairy products are very nutritious, their consumption either in normal persons or hyperlipidemic individuals and their contribution as risk 
factors for either cardiovascular diseases or hepatic disorders needs to be more clarified and more confirmed. Thus, the present study was conducted in a trial to clarify the exact relationship between increased milk or diary product consumption (either of cow of -or buffalo origin) and the increased risk for CVD and hepatic disorders in hyperlipidemic rats.

\section{MATERIAL AND METHODS}

\section{Materials}

Both fresh cow and buffalo liquid milk were obtained from the Faculty of Agriculture in Cairo University. Cholesterol powder along with bile salts that were used to induce hyperlipidemia were purchased from Laboratory Rasayan, Fine Chemical Limited, Mumbai, India, but lard was purchased from the loca market. On the other hand, ingredients used to formulate the mixtures of vitamin and salt were purchased from either Fluka (Germany) or BDH (England) Companies for Chemicals, while casein was purchased from Scerma (France) and cellulose was purchased from the Laboratory of Rasayan, Fine Chemical Limited, Mumbai, India. Most of the other ingredients of the diet, rather than the aforementioned constituents, were obtained from the local market.

Male Wistar rats used for the biological evaluation were purchased from Central Animal House at the National Research Centre, Egypt. Approval for the study protocol was obtained from the Scientific Committee of the National Research Centre (Dokki, Egypt). The animal experiment was carried out according to the stated guidelines of the Committee of Institutional Animal Care and Ethics of the NRC.

Diagnostic kit used for spectrophotometric determination of creatine phosphokinase (CK) by a kinetic method was obtained from Spinreact, S. A. U., Girona, Spain. Lactate dehydrogenase 5 (LDH-5) was assessed by ELISA ki obtained from Glory Science Co. Ltd (Del Rio, Texas, USA). Diagnostic kits that were used for spectrophotometric estimation of alanine aminotransferase (ALT), aspartate aminotransferase (AST), uric acid, creatinine, urea, total cholesterol, HDL-cholesterol and triglycerides were purchased from Salucea company, Netherlands, while kit used for assessing total lipids was purchased from Biodiagnostic Company, Egypt. The trichloroacetic acid (TCA) and the thiobarbituric acid (TBA) that were used for the evaluation of lipid peroxide product were purchased from either BDH (England) or Merck (Germany) Companies, respectively.

\section{Methods}

The fresh liquid buffalo and cow milk were allowed to dry as stated previously by Subramonian (2001) in a spray drier (The Unit of Biotechnology \& Genetic Engineering in National Research Centre, Egypt). Then, the powdered milk (both buffalo and cow) was stored at $-20{ }^{\circ} \mathrm{C}$ until using in the feeding experiment.

\section{Yogurt manufacture}

The method of Soukoulis, et al. (2007) was used for synthesizing the yogurt either from liquid cow milk or from liquid buffalo milk.

\section{Preparation of the diet}

The basal control diet has been formulated as described by Reeves et al. (1993) High fat and cholesterol diet (HFCD) that was used to induce hyperlipidemia was prepared as described by Mahmoud $\boldsymbol{e t}$ al., (2017). Briefly, $20 \mathrm{~g}$ powdered cholesterol, $2.5 \mathrm{~g}$ bile salts and $200 \mathrm{~g}$ lard were added for each $\mathrm{Kg}$ diet on the expense of starch. Then, either of the milk or the yogurt was added to the formulated HFCD diet with slight modification due to milk and yogurt chemical composition.

\section{Animal experiment}

Thirty six albino Wistar rats which were adult and of male sex of a mean body weight of $160 \pm 10 \mathrm{~g}$ were allowed to adapt for a period of one week before starting the experimental period. They were put individually into separate stainless-steel cages at a temperature of $25{ }^{\circ} \mathrm{C}$. Then, a group of six rats was separated to serve as a control negative and was fed on the basal control diet. While, the other remaining rats were fed on the diet that was high in cholesterol and fat for eight weeks to induce hyperlipidemia (Nooman et al., 2017) and continued on HFCD until the end of the feeding experiment. Hence, the feeding experiment was started with six groups of rats, each comprising 6 rats as follows: Group 1: control negative group that was fed on the basal control diet.

Group 2: control positive group that was fed on the high fat and cholesterol diet (HFCD).

Group 3: was fed on HFCD $+30 \%$ powdered buffalo milk (BM).

Group 4: was fed on HFCD $+30 \%$ powdered cow milk $(\mathrm{CM})$.

Group 5: was fed on HFCD $+30 \%$ powdered buffalo yogurt (BY).

Group 6: was fed on HFCD $+30 \%$ powdered cow yogurt $(\mathrm{CY})$.
During the experimental period, body weight change was followed as once per week, while feed intake for each rat was observed and recorded every day. After 8 weeks, the gain in body weight and the feed intake were recorded and also, feed efficiency ratio or FER was calculated as FER = Gain in body weight $/$ feed intake. Then, a fasting blood sample was obtained from the suborbital vein of each rat, after fasting for overnight, under a slight anesthesia into dry clean tubes and centrifuged at $4000 \mathrm{rpm}$ for $15 \mathrm{~min}$. The obtained serum was separated and stored at $-80^{\circ} \mathrm{C}$ until further analysis. Liver, heart and aorta from each rat were separated, washed with saline, dried on filter paper and weighed. Then, the aorta and the liver were immersed in a formalin solution (10\%) for further histopathological investigation.

\section{Biochemical analysis}

Serum lactate dehydrogenase-5 (LDH-5) was assessed by ELISA technique as described by the manufacturer's instructions and an ELISA Reader with the Model of Start $\mathrm{F}$ obtained from Awareness Technology, Inc. in Palm City (FLorida, USA) was used. The activity of creatine phosphokinase (CPK) was assessed colorimetrically by using a kinetic method as described by Gerhardt $\boldsymbol{\&}$ Waldenström (1979) and the optical density was detected using a spectrophotometer of Shimadzu model, UV-2401 PC obtained from Australia. Lipid profile was estimated as follows; serum triacylglycerols was determined by the method of Scheletter and Nussel (1975). Serum total lipids was assessed according to the method of ZÖIIner \& Kirsch (1962). Serum total cholesterol was assessed according to the method of Meiattini et al. (1978). High density lipoprotein-cholesterol or HDL-C was estimated as described by Grove (1979), while, low density lipoprotein-cholesterol or LDL-C and the very low density lipoprotein-cholesterol or VLDL-C were assessed by the method of Warnick $\boldsymbol{e} t$ al. (1990) as illustrated by the following equations:

LDL-C $=$ Total cholesterol $-($ HDL-C+ VLDL-C)

and VLDL-C $=$ Triglycerides $/ 5$

While, the Atherogenic index or A.I. was obtained from the equation that was reported by Dobiasova (2004) as follows:

A.I. (Atherogenic index $)=\log$ (triglycerides/ HDL-C).

The activities of both serum alanine amino transferase (ALT) \& aspartate amino transferase (AST) were determined as described by Henry et al. (1960). Serum creatinine and urea were estimated according to Murray (1984) and Fawcett and Scott (1960), respectively. Serum uric acid was determined according to Fossati, et al., (1980). Serum malondialdehyde or MDA was estimated as a product of lipid peroxide by the assay of thiobarbituric acid or TBA as described by Draper \& Hadley (1990).

\section{Histopathological examination}

Portions from aorta and liver for all groups were investigated histopathologically. First, they were cleared into xylol. Then, they were sectioned into 4-6 micrometer in thickness after being embedded in a paraffin. Then, they were stained with the Heamatoxylin and Eosin stain as described by Carleton (1976). Finally, all specimens were examined using a light microscope (Olympus U.TV0.5C-3) which was provided with a digital camera for the photographing of all slides.

\section{Statistical analysis}

Results were analyzed by the statistical computerized program software (SPSS), version "25" for Windows. One-way analysis of variance "ANOVA" test was carried out, then Duncan test was done. Data were tabulated as mean \pm SE. Significance level was considered at less than 0.05 , otherwise was considered as not significant.

\section{RESULTS AND DISCUSSION}

The chemical composition as well as the fatty acid content (by gas chromatography) of both milk and yogurt from either cow or buffalo origins was analyzed previously according to Halaby et al. (2015). The fat content was found to be $31,26,27.6$ and 22.4 for buffalo milk, cow milk, buffalo yogurt and cow yogurt, respectively. Also, they reported that there was a variation in the differential fatty acid content for each of buffalo milk, cow milk, buffalo yogurt and cow yogurt as analyzed by the gas chromatography technique.

\section{Feed intake, gain in body weight, feed efficiency ratio \& percent of organ weight}

Feed intake, the gain in body weight and FER or feed efficiency ratio for all groups are represented in table (1). As illustrated in the table; there is a significant decrease in feed intake for all groups when being compared with the control negative group. Also, compared to the control negative group; there is a reduction in body weight gain for all hyperlipidemic groups including the control positive group, this reduction was significant only in case of the control positive group and the hyperlipidemic group that received the buffalo yogurt, otherwise was non-significant. This may refer to the finding that hyperlipidemia induced a 
state of reduction in body weight gain. Mahmoud $\boldsymbol{e t}$ al. (2017) reported a similar result for the reduction in body weight gain in the hyperlipidemic rats. In the present study, the reduced body weight gain was restored to some extent in all hyperlipidemic groups that received milk and yogurt of either cow or buffalo origin except for the buffalo yogurt that did not show any improvement in reduced body weight gain. It is worth mentioning that in case of normal rats also, feeding them with high amounts of milk or yogurt did not exert any increase in the body weight gain as reported from a previous study (Halaby $\boldsymbol{e}$ t al., 2015).
Moreover, Kartz et al., (2014) reported that consuming dairy products that are full-cream does not increase obesity but it might have an inverse relationship with obesity, which is in accordance with the obtained results of the current study that the body weight gain of the groups which received milk or yogurt are still lower than the control negative group. On the other hand, no changes in feed efficiency ratio were noticed among different groups (Table 1).

Table 1 Feed intake, gain in body weight, FER (feed efficiency ratio), heart weight $\%$ and liver weight $\%$ of all groups

\begin{tabular}{lccccc}
\hline & \multicolumn{5}{c}{ Parameters } \\
\cline { 2 - 6 } Group & $\begin{array}{c}\text { Feed intake } \\
(\mathbf{g})\end{array}$ & $\begin{array}{c}\text { Body weight gain } \\
(\mathbf{g})\end{array}$ & FER & $\begin{array}{c}\text { Heart wt. } \\
\text { \% }\end{array}$ & $\begin{array}{c}\text { Liver wt. } \\
\text { \% }\end{array}$ \\
\hline Control Neg. & $972.47 \pm 5.75^{\mathrm{d}}$ & $207.33 \pm 10.07^{\mathrm{b}}$ & $0.213 \pm 0.01^{\mathrm{a}}$ & $0.45 \pm 0.07^{\mathrm{a}}$ & $2.87 \pm 0.13^{\mathrm{a}}$ \\
Control Pos. & $882.1 \pm 18.37^{\mathrm{ab}}$ & $168.33 \pm 12.71^{\mathrm{a}}$ & $0.191 \pm 0.01^{\mathrm{a}}$ & $0.58 \pm 0.11^{\mathrm{a}}$ & $4.48 \pm 0.47^{\mathrm{b}}$ \\
HFCD+ BM & $867.9 \pm 7.77^{\mathrm{ab}}$ & $186.83 \pm 10.35^{\mathrm{ab}}$ & $0.215 \pm 0.01^{\mathrm{a}}$ & $0.47 \pm 0.06^{\mathrm{a}}$ & $4.48 \pm 0.38^{\mathrm{b}}$ \\
HFCD + CM & $909.9 \pm 11.29 \mathrm{bc}$ & $194.5 \pm 7.08^{\mathrm{ab}}$ & $0.213 \pm 0.01^{\mathrm{a}}$ & $0.45 \pm 0.03^{\mathrm{a}}$ & $4.15 \pm 0.14^{\mathrm{b}}$ \\
HFCD + BY & $862.67 \pm 22.31 \mathrm{a}$ & $171.33 \pm 8.63^{\mathrm{a}}$ & $0.198 \pm 0.01^{\mathrm{a}}$ & $0.48 \pm 0.03^{\mathrm{a}}$ & $4.43 \pm 0.12^{\mathrm{b}}$ \\
HFCD + CY & $913.87 \pm 13.56 \mathrm{c}$ & $182.33 \pm 10.42^{\mathrm{ab}}$ & $0.199 \pm 0.01^{\mathrm{a}}$ & $0.45 \pm 0.04^{\mathrm{a}}$ & $4.40 \pm 0.22^{\mathrm{b}}$ \\
\hline
\end{tabular}

HFCD: high fat and cholesterol diet, B M: buffalo milk, C M: cow milk, B Y: buffalo yogurt, C Y: cow yogurt. Values are represented as mean \pm SE and $\mathrm{P}<0.05$ was considered as the level of significance. Values sharing the same letter either a or $\mathrm{b}$ or $\mathrm{c}$ at the same column are non-significant while, values sharing different letters at the same column are considered significant.

The heart weight percent as illustrated in table (1), showed a slightly nonsignificant increase in the control positive group compared to all other groups including the control negative group, otherwise there is no change. On the other hand, the hepatosomatic index as represented by the percentage of liver weight to body weight (table 1) had a significant elevation for the group of control positive compared to that of control negative. Similar result was obtained by Nooman $\boldsymbol{e}$ al. (2017). This increase is attributed to fat accumulation, particularly the triglycerides, in hepatocytes as mentioned by Fassini $\boldsymbol{e t}$ al. (2011). It is worth mentioning that no further increase was recorded for the hepatosomatic index of other hyperlipidemic groups that received yogurt or milk either of cow or buffalo origin despite the high fat content of the full-cream milk and yogurt indicating that this high fat content did not cause any extra fat accumulation in the liver. This finding is in accordance to some extent with that was mentioned previously by Higurashi $\boldsymbol{e t}$ al. (2016) who concluded from their study that consumption of milk products, in particular the cheese, prevents accumulation of fat in hepatocytes in rats that received a diet with elevated fat content as it kept the liver weight percent of the hyperlipidemic rats that were fed on cheese lower than its corresponding weight of the hyperlipidemic rats that did not receive cheese.

\section{Kidney function}

As shown in Table (2) there was a significant increase in serum urea for al hyperlipidemic groups compared to the control negative group, while there were no changes for the other two parameters which are the serum creatinine and uric acid among all groups. Similar results were reported in other studies (Kassem $\boldsymbol{e}$ al., 2011).

$\underline{\text { Table } 2 \text { Serum urea, creatinine and uric acid concentration of all groups }}$

\begin{tabular}{lccc}
\hline \multirow{2}{*}{ Groups } & \multicolumn{3}{c}{ Parameters } \\
\cline { 2 - 4 } & $\begin{array}{c}\text { Urea } \\
(\mathbf{m g} / \mathbf{d l})\end{array}$ & $\begin{array}{c}\text { Creatinine } \\
(\mathbf{m g} / \mathbf{d l})\end{array}$ & $\begin{array}{c}\text { Uric acid } \\
(\mathbf{m g} / \mathbf{d l})\end{array}$ \\
\hline Control Neg. & $31.95 \pm 2.21^{\mathrm{a}}$ & $0.63 \pm 0.02^{\mathrm{a}}$ & $1.32 \pm 0.09^{\mathrm{a}}$ \\
Control Pos. & $42.9 \pm 3.41^{\mathrm{b}}$ & $0.59 \pm 0.08^{\mathrm{a}}$ & $1.40 \pm 0.15^{\mathrm{a}}$ \\
HFCD+ BM & $45.88 \pm 3.56^{\mathrm{b}}$ & $0.59 \pm 0.04^{\mathrm{a}}$ & $1.40 \pm 0.11^{\mathrm{a}}$ \\
HFCD + CM & $47.4 \pm 2.98^{\mathrm{b}}$ & $0.61 \pm 0.04^{\mathrm{a}}$ & $1.07 \pm 0.06^{\mathrm{a}}$ \\
HFCD + BY & $39.4 \pm 3.12^{\mathrm{a}}$ & $0.56 \pm 0.05^{\mathrm{a}}$ & $1.33 \pm 0.15^{\mathrm{a}}$ \\
HFCD + CY & $44.67 \pm 2.85^{\mathrm{b}}$ & $0.60 \pm 0.05^{\mathrm{a}}$ & $1.42 \pm 0.24^{\mathrm{a}}$ \\
\hline
\end{tabular}

HFCD: high fat and cholesterol diet, B M: buffalo milk, C M: cow milk, B Y: buffalo yogurt, $\mathrm{C} Y$ : cow yogurt. Values are expressed as mean $\pm \mathrm{SE}$ and the mean difference is significant at $\mathrm{P}<0.05$. Values that share the same letter $(\mathrm{a}, \mathrm{b}$ or $\mathrm{c})$ in the same column are not significant while, values that share different letters in the same column are significant.

\section{Lipid parameters and atherogenic index}

Keeping rats on a diet high in fat and cholesterol has led to a state of hyperlipidemia as evidenced from the increased concentration of serum total lipids, triglycerides, total cholesterol, LDL-C and VLDL-C and the reduction of HDL-C (Table 3) for the control positive group compared to the control negative group. No further elevation was recorded for T. lipids, TG, TC, LDL-C or VLDL-C and no further reduction in HDL-C in the hyperlipidemic groups that received yogurt or milk either from cow or buffalo origin although full-cream. Instead, the alterations that were noticed in the aforementioned parameters due to hyperlipidemia were changed to near normalization in all hyperlipidemic groups that received yogurt or milk either from cow or buffalo origin with different extents (except for that group which received buffalo milk) so that they became non-significant compared with control negative group in case of total lipids, TG, HDL-C and VLDL-C. In this respect, Wat et al. (2009) stated that epidemiological studies highlighted the negative correlation between high milk and other dairy products consumption and the cardiovascular diseases risk factors such as dyslipidemia. Also, a previous study for our team revealed that consumption of either milk or yogurt although full cream with two levels $(15 \%$ or $30 \%$ ) in normal rats did not elevate lipid markers or the atherogenic index (Halaby et al., 2015). Although each of buffalo milk, cow milk, buffalo yogurt and cow yogurt contain considerable amounts of saturated fat (butyric, myristic, capric, capruic, caprylic, lauric, stearic and palmitic acids with myristic, stearic and palmitic acids having the highest values) as reported previously by Halaby $\boldsymbol{e}$ al. (2015), yet milk and dairy products was said to minimize the intestinal cholesterol and fat absorption for rodents (Millar et al., 2020). This was explained on the basis that milk fat globules are encased naturally in membrane for milk fat globule which is a rich structure in polar lipids, as sphingomyelin. The latter is considered as a bioactive phospholipid that contribute in lowering intestinal fat absorption which in turn prevent any extra increase in lipid parameters in the circulation, instead it lowers significantly most of the serum lipid parameters. However, in case of TC and LDL-C, the improvement in the same aforementioned groups was slight but still significantly changed from the control negative group. Also, it can be noticed that the hyperlipidemic group that was fed on buffalo milk showed the least improvement among all other groups that received yogurt or milk. It was reported before in a previous study (Halaby et al., 2015) that the buffalo milk has the highest fat content with a value of $31 \%$ versus; $27.6 \%, 26.9 \%$ \& $22.4 \%$ for cow milk, buffalo yogurt and cow yogurt, respectively. Also, the atherogenic index (Fig. 1) showed improvement in all hyperlipidemic groups that received either buffalo milk or cow milk or buffalo yogurt or cow yogurt comparing with the control positive group with the best improvement was in the cow yogurt group.

Table 3 Lipid profile of all groups

\begin{tabular}{lcccccc}
\hline & \multicolumn{7}{c}{ Parameters } \\
\cline { 2 - 7 } Group & $\begin{array}{c}\text { Total lipids } \\
(\mathbf{m g} / \mathbf{d l})\end{array}$ & $\begin{array}{c}\text { TG } \\
(\mathbf{m g} / \mathbf{d l})\end{array}$ & $\begin{array}{c}\text { TC } \\
(\mathbf{m g} / \mathbf{d l})\end{array}$ & $\begin{array}{c}\text { HDL-C } \\
(\mathbf{m g} / \mathbf{d l})\end{array}$ & $\begin{array}{c}\text { LDL-C } \\
(\mathbf{m g} / \mathbf{d l})\end{array}$ & $\begin{array}{c}\text { VLDL-C } \\
(\mathbf{m g} / \mathbf{d l})\end{array}$ \\
\hline Control Neg. & $385.18 \pm 22.69^{\mathrm{a}}$ & $91.30 \pm 6.35^{\mathrm{a}}$ & $95.12 \pm 10.34^{\mathrm{a}}$ & $22.12 \pm 2.80^{\mathrm{a}}$ & $54.73 \pm 11.79^{\mathrm{a}}$ & $18.27 \pm 3.27^{\mathrm{a}}$ \\
Control Pos. & $726.5 \pm 76.91^{\mathrm{c}}$ & $150.4 \pm 4.01^{\mathrm{b}}$ & $190.70 \pm 26.63^{\mathrm{b}}$ & $15.36 \pm 0.88^{\mathrm{b}}$ & $150.93 \pm 30.42^{\mathrm{b}}$ & $30.07 \pm 2.80^{\mathrm{b}}$ \\
HFCD + BM & $556.55 \pm 71.27^{\mathrm{b}}$ & $141.68 \pm 7.82^{\mathrm{b}}$ & $175.59 \pm 13.29^{\mathrm{b}}$ & $20.20 \pm 1.85^{\mathrm{b}}$ & $127.05 \pm 14.36^{\mathrm{b}}$ & $28.33 \pm 1.56^{\mathrm{b}}$ \\
HFCD + CM & $516.65 \pm 27.09^{\mathrm{ab}}$ & $116.41 \pm 7.39^{\mathrm{ab}}$ & $146.78 \pm 18.56^{\mathrm{ab}}$ & $20.83 \pm 2.89^{\mathrm{ab}}$ & $111.33 \pm 12.91^{\mathrm{b}}$ & $23.29 \pm 1.48^{\mathrm{ab}}$ \\
HFCD + BY & $503.78 \pm 35.29^{\mathrm{ab}}$ & $124.97 \pm 20.19^{\mathrm{ab}}$ & $165.16 \pm 17.53^{\mathrm{b}}$ & $21.95 \pm 0.76^{\mathrm{a}}$ & $118.20 \pm 18.77^{\mathrm{b}}$ & $24.97 \pm 4.04^{\mathrm{ab}}$ \\
HFCD + CY & $503.78 \pm 35.29^{\mathrm{ab}}$ & $124.08 \pm 5.03^{\mathrm{ab}}$ & $187.36 \pm 13.37^{\mathrm{b}}$ & $20.5 \pm 1.58^{\mathrm{ab}}$ & $142.25 \pm 15.09^{\mathrm{b}}$ & $24.82 \pm 1.00^{\mathrm{ab}}$ \\
\hline
\end{tabular}

HFCD: high fat and cholesterol diet, B M: buffalo milk, C M: cow milk, B Y: buffalo yogurt, C Y: cow yogurt. Values are represented as mean \pm SE and $\mathrm{P}<0.05$ was considered as the level of significance. Values sharing the same letter either $\mathrm{a}$ or $\mathrm{b}$ or $\mathrm{c}$ at the same column are non-significant while, values sharing different letters at the same column are considered significant. 


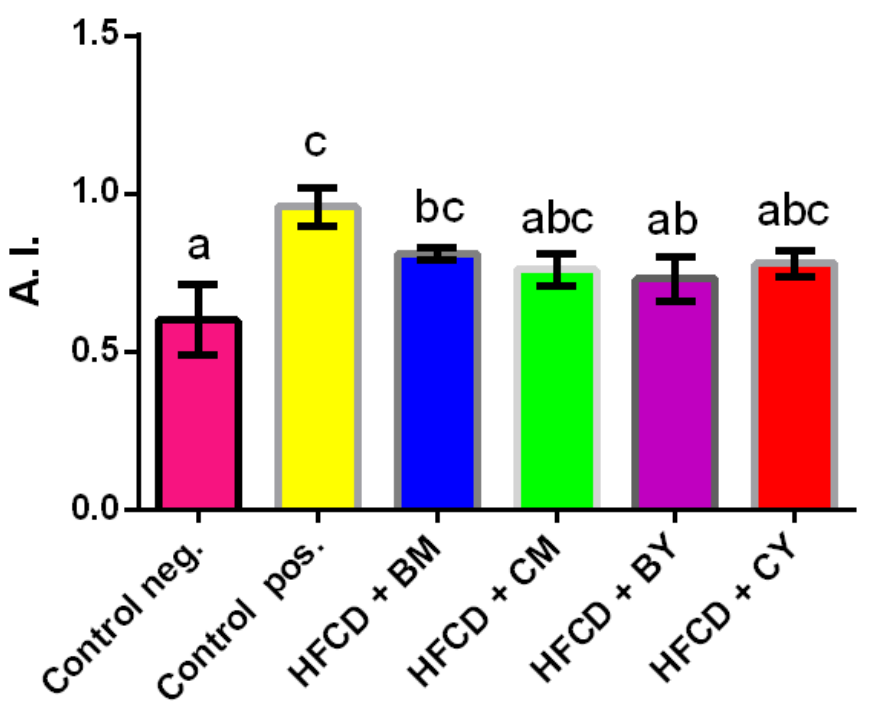

Groups

Figure 1 Atherogenic index (A. I.) of all groups. Columns that share the same letter (a, b or c) have non-significant values while, those that share different letters are of significant values.

\section{Cardiac and liver markers}

In the present study, the state of hyperlipidemia that was achieved by keeping rats on a diet high in fat and cholesterol affected the liver and heart enzymes negatively. This is evidenced by the significant increased activity of CPK and AST for the control positive group when being compared with the group of control negative (Fig 2- A \& B). CPK is considered as a cardiac biomarker (Wallimann \& Hemmer, 1994) and also AST to a lesser extent (as the two enzymes are found in other tissues but predominantly in the heart tissue). Their increased activity, in particular CPK, in the serum is indicative of myocardial injury (Alexander et al.,2007 \& Michael et al., 2010). Increased activity of CPK and AST may be due to increased lipid peroxidation of the cardiomyocytes membranes as noticed from the obtained results of increased malondialdehyde of the control positive group (Fig. 2-E) which in turn led to increasing permeability of cells and hence, leakage of enzymes from cardiomyocytes into the circulation and hence, increased activity in serum (Recchioni $\boldsymbol{e t}$ al., 2013 \& El-Shobaki $\boldsymbol{e}$ al., 2018). Also, liver enzymes; AST and ALT showed increased activity for rats of the group of control positive comparing with those of the group of control negative (Fig 2-B \& C). This result was also reported previously in many studies (Nooman et al., 2017 and Mahmoud et al., 2017). In addition, the isoenzyme LDH-5 showed a significant increase in the control positive group compared to the control negative group (Fig 2-D). This isoenzyme was reported previously to be found in its highest amount in the cells of liver and skeletal muscles (Dasgupta \& Wahed, 2014), thus its increased activity (together with the increased activity of other liver enzymes) in the serum may be considered as indicative biomarkers for any injury of hepatocytes. This increase in serum activity of hepatic enzymes may be attributed to accumulation of fat in hepatocytes affecting their capacity for performing their normal functions (Mahmoud et al., 2017). Also, it may be explained again on the basis of increased lipid peroxidation of hepatocyte membranes as evidenced by the significant elivation in serum levels of malondialdehyde that was recorded for the control positive group comparing it with the group of control negative (Fig 2-E) In this respect, increased lipid peroxidation was reported before to occur as a result of increased oxidative stress in rats (Mahmoud $\boldsymbol{e t}$ al., 2018). Nooman et al. (2017) added that keeping rats on a high cholesterol and fat diet increased the oxidative stress which in turn led to the elevation of serum lipid peroxide concentration in rats. Increased lipid peroxidation of hepatocytes rendered it more permeable for proteins and hence leakage of the liver enzymes into the circulation (Masarone et al., 2018). Activities of both CPK and LDH as well as malondialdehyde concentration showed a marked and significant improvement in the hyperlipidemic groups that received yogurt or milk either from cow or buffalo origin with different extents as seen in Fig (2- A, D \& E), respectively. The improvement of serum CPK (Fig. 2-A) together with the improvement of the atherogenic index (Fig. 1) in the present study indicate that consumption of milk and yogurt, although full-cream, yet it can protect heart and lower the risk for cardiovascular diseases. Millar et al. (2020) concluded from their epidemiological study that moderate consumption of milk showed a lower risk of mortality from cardiovascular diseases. Although saturated fat constitutes the greater proportion of dairy fat compared to other common dietary fats, yet there is no evidence that implicate dairy products as CVD risk promoters (Praagman et al., 2016). The insufficiency of detrimental impacts associated with the intake of dairy fat may be due to modulation of the health response by the dairy matrix to cholesterol and saturated fat (Thorning et al., 2017). On the other hand, AST and ALT activities (fig 2- B \& C) have recorded a very slight improving for the same groups, meaning that consumption of full-cream milk and yogurt in hyperlipidemic persons does not increase the severity of hyperlipidemia, instead, it lowers, although slightly, the increased activity of liver enzymes, thus, help hepatocytes for performing their functions normally. Results obtained from the study conducted by Higurashi et al. (2016) may reinforce our findings, since they reported that consumption of cheese prevent accumulation of fat in hepatocytes when feeding rats on a high fat diet.
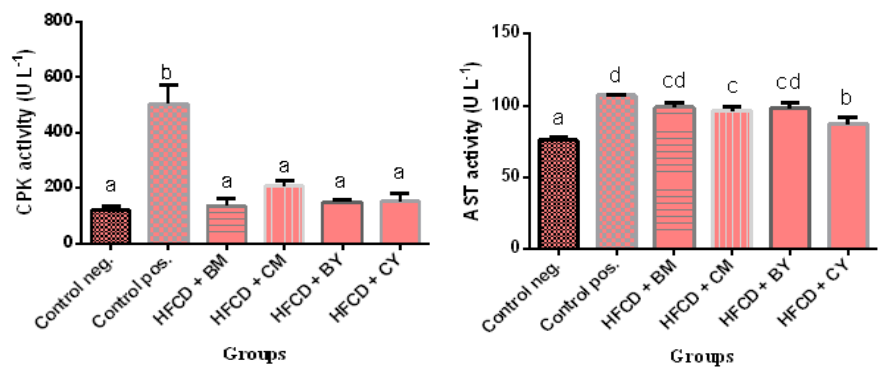

A

B
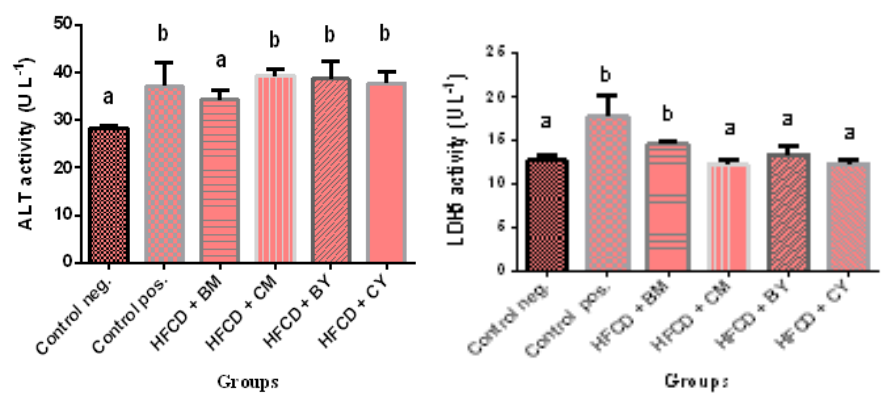

D

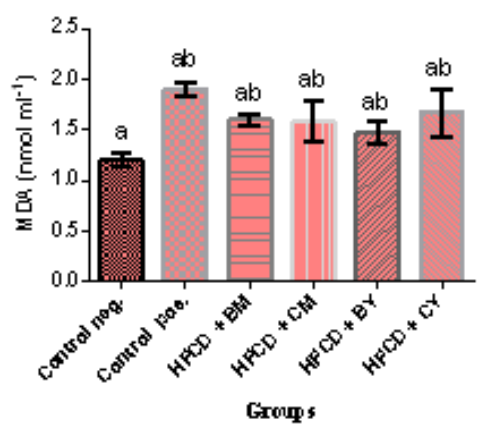

$\mathbf{E}$

Figure 2 Activity of serum cardiac and liver enzymes and serum malondialdehyde concentration; A- Activity of CPK. B- Activity of AST. C- Activity of ALT. D- Activity of LDH-5. E- Concentration of malondialdehyde. Columns sharing the same letter either a or b or $\mathrm{c}$ or $\mathrm{d}$ have non-significant values while, those sharing different letters were considered significant.

\section{Histopathological examination}

Results obtained from the histopathological examination of the aorta confirms the biochemical findings for the cardiac biomarkers. It is obvious that the control positive group (Fig. 3-b) shows vacuolation of tunica medica, while the other hyperlipidemic groups that received yogurt or milk either from buffalo or cow origin (Fig. 3-c, d, e \& f) show normalization of the histopathological examination, except for the hyperlipidemic group that were fed on cow milk which still shows vacuolation of the tunica medica.

On the other hand, a slight improvement was seen for the histopathological examination of the hepatic tissue of the hyperlipidemic groups that received yogurt or milk either from buffalo or cow origin (Fig. 4- c, d, e \& f) which shows only fatty changes with the absence of inflammatory cell infiltration compared to the control positive group (Fig. 4-b) that shows fatty changes with inflammatory cell infiltration. But the hyperlipidemic group that was fed on buffalo milk did not record any improvement. In fact, these results come in agreement with the biochemical results obtained for liver. Thus, it can be stated that histopathological examination for both cardiac and hepatic tissues more or less reinforces the biochemical findings. 


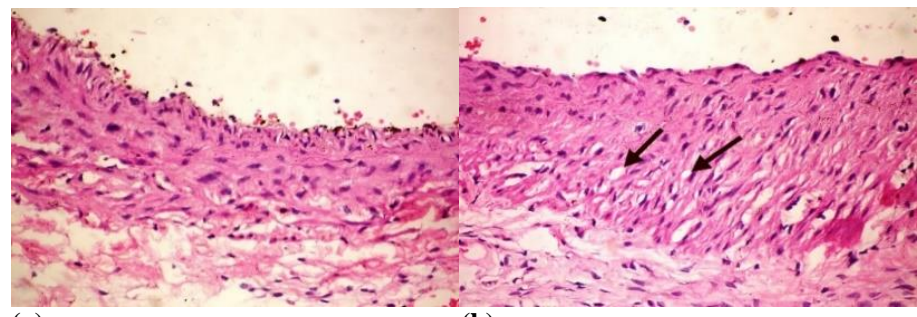

(a) (b)

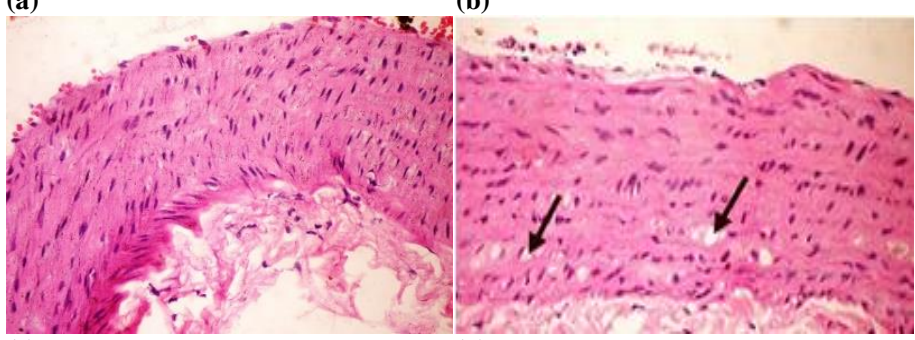

(c)

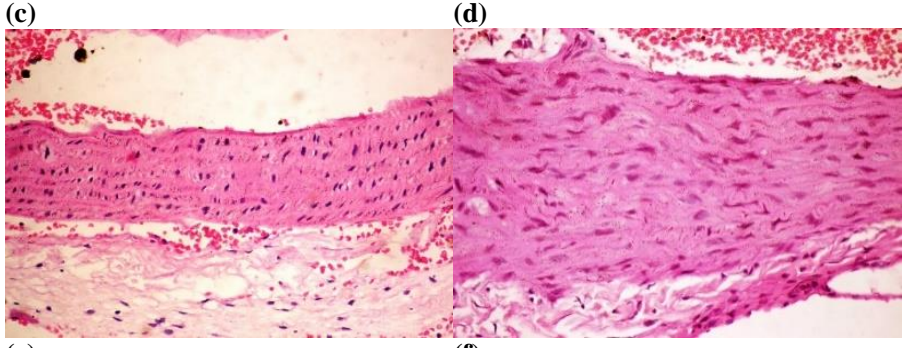

(e)

(f)

Figure 3 (a) Aorta of a rat from the group of control negative showing no change in.histopathological examination (b) Aorta of rat from control positive group showing vacuolation of tunica media (c) Aorta of rat from the group of HFHC + buffalo milk showing no histopathological changes. (d) Aorta of rat from the group of HFHC + cow milk showing slight vacuolation of tunica media. (e) Aorta of rat from the group of HFHC + buffalo yogurt showing no changes in histopathological examination. (f) Aorta of a rat from $\mathrm{HFHC}+\mathrm{cow}$ yogurt group showing no histopathological changes. (H \& E X 400).
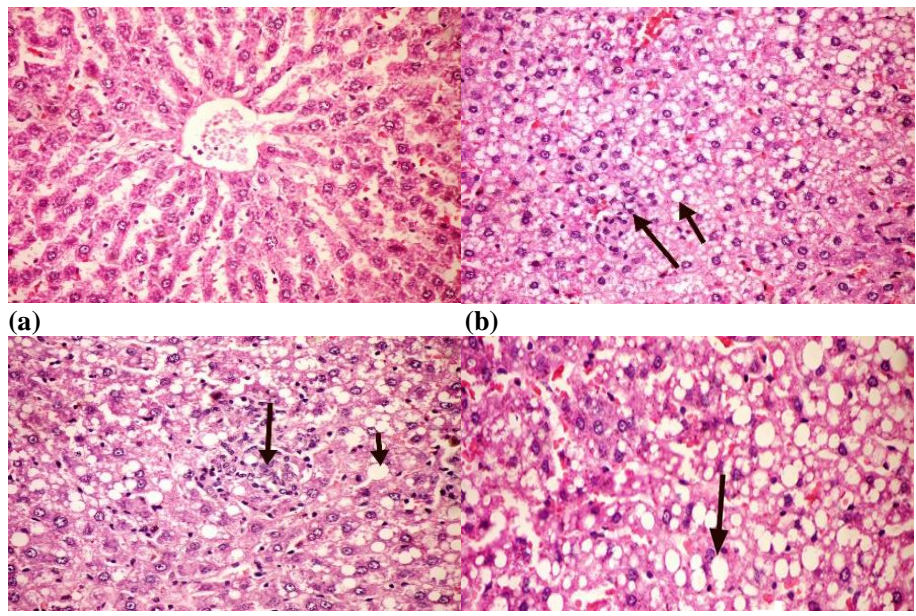

(c)

(d)

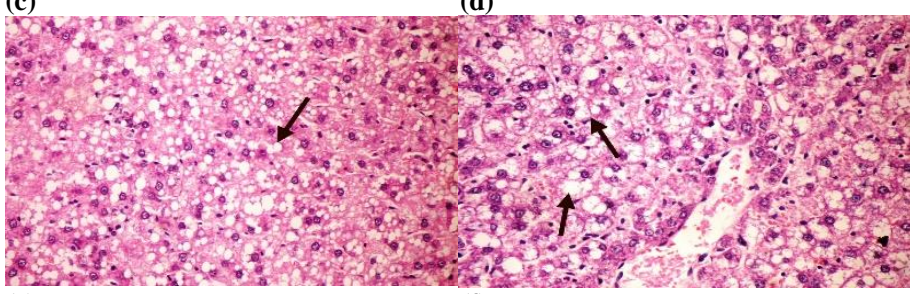

(e)

(f)

Figure 4 (a) Liver of a rat from the group of control negative showing no changes in histopathological architecture (b) Liver of rat from control positive group showing fatty change of hepatocytes and focal hepatic necrosis associated with inflammatory cells infiltration (c) Liver of rat from the group of HFHC + buffalo milk showing fatty change of hepatocytes and focal hepatic necrosis associated with inflammatory cells infiltration (d) Liver of rat the group of HFHC + cow milk showing fatty change of hepatocytes (e) Liver of rat from the group of HFHC + buffalo yogurt showing fatty change of hepatocytes (f) Liver of rat from the group of HFHC + cow yogurt showing fatty change of hepatocytes ( $\mathrm{H} \& \mathrm{E} \mathrm{X}$ 400).

\section{CONCLUSION}

The results of the present study demonstrate that increased consumption of milk and yogurt either of buffalo or cow origin did not exert any negative impact on liver but it restored the activity of liver enzymes and LDH-5 to some extent. It did not also increase hepatic fat deposition as represented by the unchanged hepatosomatic index for the hyperlipidemic groups that were fed on milk and yogurt compared to the control positive group. Also, the high milk or yogurt consumption not only have no adverse impact on the cardiovascular health, but on the contrary improved the cardiovascular state as represented by restoring the increased activity of the cardiac biomarker; the CPK enzyme and reducing the atherogenic index. Above all, high consumption of milk or yogurt counteract to some extent the state of hyperlipidemia by improving the disturbed lipid parameters. Thus, milk and yogurt consumption is safe in hyperlipidemic individuals.

Acknowledgments: Authors would like to thank the pathologist; Prof. Kawkab Abd-elaziz Ahmed, the Professor of Pathology in Faculty of The Veterinary Medicine, Cairo University for carrying out the histopathological examination.

\section{REFERENCES}

Ahmad, S., Anjum, F. M., Huma, N., Sameen, A. \& Zahoor, T. (2013). The Composition and physico-chemical characteristics of buffalo milk with particular emphasis on lipids, proteins, minerals, enzymes and Vitamins. Journal of Animal and Plant Sciences, 23(1 Suppl.), 62-74.

Alexander, K. P., Newby, L. K., Armstrong, P. W., et al.,.( 2007). Acute coronary care in the elderly, part II:ST-segment-elevation myocardial infarction a scientific statement for health care professionals from the American Heart Association Council on Clinical Cardiology: in collaboration with the Society of Geriatric Cardiology. Circulation, 115:2549-69. http://doi.org/10.1161/CIRCULATIONAHA.107.182615

Berger, A., Turini, M. E., \& Colarow, L., (2005). Buffalo milk gangliosides. US Patent No. 20, 050, 107, 311.

Carleton, H. (1976). Histological Technique. 4 Th Ed. (Vol. 37). London, Oxford University Press, New York, Toronto. Chemists' Society, Chicago, pp., 447-451. Chartier, D. J. P., Cote, J. A., Labonte, M. E., et al. (2016). Comprehensive review of the impact of dairy foods and dairy fat on cardiometabolic risk. Advances in nutrition (Bethesda, Md), 7, 1041-1051. https://doi.org/10.3945/an.115.011619

Dasgupta, A., Wahed, A., (2014). Clinical Chemistry, Immunology and Laboratory Quality Control. A Comprehensive Review for Board Preparation, Certification and Clinical Practice. Hardcover ISBN: 9780124078215, eBook ISBN: 9780124079359, Imprint: Elsevier.

Dobiášová, M., (2004). Atherogenic Index of Plasma [Log(Triglycerides/HDLCholesterol)]: Theoretical and Practical Implications. Clin. Chem. 50, 113-115 http://doi. org/10.1373/clinchem.2004.033175

Draper, H., Hadley, M. (1990). Malondialdehyde determination as index of lipid Peroxidation. Methods Enzymol. 186, 421-431. https://doi.org/10.1016/0076 6879(90)86135-I

Wat, E., Tandy, S., Kapera, E., Kamili, A., Chung, R. W. S., Brown, A., Rowney, M., Cohn, J. S. (2009). Dietary phospholipid-rich dairy milk extract reduces hepatomegaly, hepatic steatosis and hyperlipidemia in mice fed a high-fat diet hepatic steatosis and hyperlipidemia in mice fed a high-fat diet. Atherosclerosis, 205, 144-150

El-Maksoud, A. A., Korany, R. M. S., Abd El-Ghany, I. H., El-Beltagi, H. S. Gustavo, M., de Gouveia, A. F. (2020). Dietary solutions to dyslipidemia: Milk protein-polysaccharide conjugates as liver biochemical enhancers. J Food Biochem. 00: e13142. https://doi.org/10.1111/jfbc.13142

El-Shobaki, F. A., Wahba, H. M. A., Mahmoud, M. H., Kazem, Y. I., Badawy, I H., Zahran, A. S., (2018). Formulation and evaluation of an adaptogenic formula to improve performance of athletes practicing anaerobic exercises. Journal of Biological Sciences, 18(5): 231-242. http://doi.org/10.3923/jbs.2018.231.242

Fassini, P. G., Noda, R. W., Ferreira, E. S., Silva, M. A., Neves, V. A., Demonte, A. (2011). Soybean glycinin improves HDL-C and suppresses the effects of rosuvastatin on hypercholesterolemic rats. Lipids Health Dis. 10, 1. https://doi. org/10.1186/1476-511X-10-165

Fawcett J, Scott J. (1960). A rapid and precise method for the determination of urea. J. Clin. Pathol. 13, 156-159. https:// doi.org/10.1136/jcp.13.2.156

Fontecha, J., Calvo, M.V., Juarez, M., et al.(2019). Milk and dairy product consumption and cardiovascular diseases: an overview of systematic reviews and meta-analyses. Advances in nutrition (Bethesda, Md), 10, S164-S189. https://doi.org/10.1093/advances/nmy099

Fossati,,P., Prencipe, L. \& Berti,G. ( 1980). Use of 3,5-dichloro-2hydroxybenzene-sulfonic acid/4-aminophenazone chromogenic system in direct enzymatic assay of uric acid in serum and urine. Clinical chemistry, 26, 227-231. Gerhardt, W. \& Waldenström, J., (1979). Creatine kinase B-subunit activity in serum after immunoinhibition of M-subunit activity. Clinical Chemistry, 25(7), 1274-1280. 
Grove, T. H. (1979). Effect of reagent $\mathrm{pH}$ on determination of high-density lipoprotein cholesterol by precipitation with sodium phosphotungstatemagnesium. Clin. Chem. 25, 560-564.

Halaby, M. S., Farag, M. H., Mahmoud, M. H., Badawy, I. B., Abd Rabou, N. S \& Mohammed, F. S. (2015). Effect of consumption of Milk and Yogurt on Lipid metabolism and Atherosclerosis in adult male rats. International Journal of ChemTech Research, 8 (10), 388 - 398.

Hassan, A. \& Amjad, I., (2010). Nutritional Evaluation of Yoghurt Prepared by Different Starter Cultures and Their Physiochemical Analysis during Storage African Journal of Biotechnology, 9, 2913-2917.

He, M., Guo, Z., Lu, Z. \& Wei, S., (2020). High milk consumption is associated with carotid atherosclerosis in middle and old-aged Chinese. International Journal of Cardiology Hypertension, 5, 100031.

Henry, R., Chiamori, M., Golub, O. \& Berkman S. (1960). Revised spectrophotometric methods for the determination of glutamate oxaloacetic transaminase, glutamic pyruvate transaminase and lactic acid dehydrogenase Am. J. Clin. Pathol. 34, 381-398.

Higurashi, S., Ogawal, A., Nara, T. Y., Kato, K., \& Kadooka Y., (2016). Cheese consumption prevents fat accumulation in the liver and improves serum lipid parameters in rats fed a high-fat diet. Dairy Sci. \& Technol., 96, 539-549. http://doi.org/10.1007/s13594-016-0288-z

Karr, S. (2017). Epidemiology and Management of Hyperlipidemia. Am J Managed Care, 23, S139-S148.

Kassem, S. S., Mahmoud, M. H., Abdel-Kader, M. M. \& El-Shobaki, F. A (2011). Evaluation of the Health Value of some Beverages Prepared from Vegetable and Fruit Wastes. Journal of American Science,7(9), 328-339.

Kratz, M., Marcovina, S., Nelson, J., Yeh, M., Kowdley, K., Callahan, H., Song, X. \& Utzschneider, K. (2014). Dairy fat intake is associated with glucose tolerance, hepatic and systemic insulin sensitivity, and liver fat but not $\beta$-cell function in humans. Am J Clin Nutr. 99(6):1385-1396.

Lin, F. C., Chang, Y. H., Chien, S. C., Lin, Y. H. \& Yeh H. Y., (2018) Epidemiology of Dyslipidemia in the Asia Pacific Region. International Journal of Gerontology, 12, 2-6.

Liu, C., Shen, Y. J., Tu, Q. B., Zhao, Y. R., Guo, H., Wang, J., Zhang, L., Shi, H W. \& Sun, Y., (2018). Pedunculoside, a novel triterpene saponin extracted from Ilex rotunda, ameliorates high-fat diet induced hyperlipidemia in rats. Biomed. Pharmacother., 101, 608-616.

Mahmoud, M. H., Wahba, H. M. A., Mahmoud, M. H., Badawy, I. H. (2017) Newly Formulated Antioxidant Rich Dietary Supplement in Jelly Form for Alleviation of Liver Diseases in Rats. Journal of Biological Sciences, 17 (7), 334-346.

Mahmoud, M. H., Wahba, H. M. A., Mahmoud, M. H., Abu-Salem, F. M. (2018) Antagonizing the Hazardous Impact of Increased Oxidative Stress in Wistar Rats by Biscuits with Dried Orange Peel. Journal of Biological Sciences., 18(1), 21 31.

Masarone, M., Rosato, V., Dallio, M., et al. (2018). Role of Oxidative Stress in Pathophysiology of Nonalcoholic Fatty Liver Disease. Oxidative Medicine and Cellular Longevity, Article ID 9547613, 14 pages. https://doi.org/10.1155/2018/9547613

Meiattini, F., Prencipe, L., Bardelli, F., Giannini, G. \& Tarli P. (1978). The 4 hydroxybenzoate/4-aminophenazone chromogenic system used in the enzymic determination of serum cholesterol. Clin. Chem. 24, 2161-2165.

Michael, C., Kontos, M. C., Diercks, D. B. \& Kirk, J. D., (2010). Emergency Department and Office-Based Evaluation of Patients with Chest Pain. Mayo Clin. Proc., 85(3), 284-299. http://doi.org.10.4065/mcp.2009.0560

Millar, C. L., Jiang, C., Norris, G. H., Garcia, C., Seibel, S., Anto, L., Lee, J. Y. \& Blesso, C. N. (2020). Cow's milk polar lipids reduce atherogenic lipoprotein cholesterol, modulate gut microbiota and attenuate atherosclerosis development in LDL-receptor knockout mice fed a Western-type diet. Journal of Nutritional Biochemistry, 79, 108351 .

Mishali, M., Prizant-Passal, S., Avrech, T., et al. (2019). Association between dairy intake and the risk of contracting type 2 diabetes and cardiovascular diseases: a systematic review and meta-analysis with subgroup analysis of men versus women. Nutr. Rev., 77, 417-429. https://doi.org/10.1093/nutrit/nuz006, $\underline{2019 / 06 / 22}$

Mozaffarian, D., Benjamin, E. J., Go, A. S., et al. (2016). Heart disease and stroke statistics - 2016 update: a report from the American Heart Association. Circulation, 133(4), e38-e360. http://doi.org/10.1161/CIR.0000000000000350

Murray, R. L. (1984). Creatinine, In Clinical Chemistry, Theory, Analysis and Correlation. Kaplan LA and Pesce AJ (Eds.). CV Mosby Co., St. Louis, pp.1247-1253.

Nooman, M. U., Mahmoud, M. H., Al-kashef, A. S., Rashad, M. M. (2017). Hypocholesterolemic impact of newly isolated sophorolipids produced by microbial conversion of safflower oil cake in rats fed on high fat and cholesterol $\begin{array}{llllll}\text { diet. } & \text { Grasas } & y & \text { Aceites, } & 68 & \text { (3), }\end{array}$ http://dx.doi.org/10.3989/gya.0219171

Praagman, J., Beulens, J. W., Alssema, M., Zock, P. L., Wanders, A. J., Sluijs, I. et al. (2016). The association between dietary saturated fatty acids and ischemic heart disease depends on the type and source of fatty acid in the European
Prospective Investigation into Cancer and Nutrition-Netherlands cohort. Am J Clin Nutr, 103, 356-65.

Recchioni, R., Marcheselli, F., Olivieri, F., Ricci, S., Procopio, A. D., Antonicelli, R. (2013). Conventional and novel diagnostic biomarkers of acute myocardial infarction: a promising role for circulating microRNAs, Biomarkers, 18, 547-558.

Reda, A., Elserafy, A. S., Farag, E., et al. (2020). Egyptian Association of Vascular Biology and Atherosclerosis (EAVA) consensus on the usage of proprotein convertase subtilisin/kexin type 9 (PCSK9) inhibitors. The Egyptian Heart Journal, 72, 23-28. https://doi.org/10.1186/s43044-020-00058-0

Reeves, P. G., Nielsen, F. H,, Fahey, Jr. G. C. (1993). AIN-93 purified diets for laboratory rodents: final report of the American Institute of Nutrition ad hoc writing committee on the reformulation of the AIN-76A rodent diet. J. Nutr. 123 , 1939-1951.

Sacks, F. M., Lichtenstein, A. H., Wu, J. H. Y., et al. (2017). Dietary fats and cardiovascular disease: a presidential advisory from the American heart association. Circulation, 136, e1-e23. https://doi.org/10.1161/cir.0000000000000510

Santos, N. W., Yoshimura, E. H., Mareze-Costa, C. E., et al. (2017) Supplementation of cow milk naturally enriched in polyunsaturated fatty acids and polyphenols to growing rats. PLoS ONE, 12(3), e0172909. http://doi.org/10.1371/journal.pone.0172909

Scheletter, G. \& Nussel, E. (1975). Quantitative enzymatic Colorimetric determination of triglycerides in serum or plasma. Arbeitsmed Sozialmed Pracentimed. 10, 25.

Sheehan, W. J. \& Phipatanakul, W., (2009). Tolerance to water buffalo milk in a child with cow allergy. Allergy Asthma and Immunology, 102, 349.

Soukoulis, C., Panagiotidis, P., Koureli, R., \& Tzia, C. (2007). "Industrial Yogurt Manufacture: Monitoring of Fermentation Process and Improvement of Final Product Quality". J. Dairy Sci., 90, 2641-2654.

Subramonian, B. S. (2001). Studies on preparation of dietetic milk powder with added bifidogenic properties. Ph. D., Thesis submitted to Tamil Nadu Veterinary and Animal Sciences University, Tamil Nadu, India.

Thorning, T. K., Bertram, H. C., Bonjour, J. P., de Groot, L., Dupont, D., Feeney, E., et al. (2017). Whole dairy matrix or single nutrients in assessment of health effects: current evidence and knowledge gaps. Am J Clin Nutr., 105, 1033-45. Uscanga-Domínguez, L. F., Orozco-García, I. J., Vázquez-Frias, R., et al., (2019). Technical position on milk and its derivatives in adult health and disease from the Asociación Mexicana de Gastroenterología and the Asociación Mexicana de Gerontología y Geriatría. Revista de Gastroenterología de México, 84(3): 357-371.

Wallimann T. \& Hemmer W. (1994). 111-2 Creatine kinase in non-muscle tissues and cells. Molecular and Cellular Biochemistry, 1331134, 193-220.

Warnick, G. R., Knopp, R. H., Fitzpatrick, V. \& Branson, L. (1990). Estimating low-density lipoprotein cholesterol by the Friedewald equation is adequate for classifying patients on the basis of nationally recommended cutpoints. Clin Chem. 36, 15-19.

Yang, B., Xuanb, S.\& Ruanb, Q., (2020). UPLC/Q-TOF-MS/MS-based metabolomics revealed the lipid-lowering effect of Ilicis Rotundae Cortex on high-fat diet induced hyperlipidemia rats. Journal of Ethnopharmacology, 256 112784. https://doi.org/10.1016/j.jep.2020.112784

Zhang, S., Fu, J.\& Zhang Q., (2020). Association between habitual yogurt consumption and newly diagnosed non-alcoholic fatty liver disease. European Journal of Clinical Nutrition, 74, 491-499. https://doi.org/10.1038/s41430-019. 0497-7

ZÖllner, N. \& Kirsch, K., (1962). Colorimetric method for determination of total lipids. Journal of Experimental Medicine, 135, 545-550. 